\title{
Meta-Analisis Konsep Penerapan Metode E-Learning pada Universitas Muhammadiyah Se-Jawa Tengah
}

\author{
Meta-Analysis of E-Learning Implementation Method Concept of \\ Muhammadiyah University in Central Java \\ Denis Pratama Alwan Azzami ${ }^{1}$, Hindayati Mustafidah ${ }^{2}$ \\ ${ }^{1,2}$ Teknik Informatika, Universitas Muhammadiyah Purwokerto \\ Jalan Raya Dukuhwaluh Purwokerto, Jawa Tengah, Indonesia \\ 1denisalwan21@gmail.com \\ ${ }^{2}$ fida.mustafidah@ump.ac.id
}

\begin{abstract}
ABSTRAK
Mutu pendidikan menjadi tolak ukur keberhasilan sebuah instansi pendidikan untuk dapat survive dalam anomali perubahan zaman. Maka dari itu pemanfaatan teknologi dan informasi sangat menjadi kebutuhan yang harus bersinergi dalam dunia pendidikan. Pengembangan pendidikan menggunakan e-learning merupakan suatu kebutuhan agar standar mutu pendidikan dapat ditingkatkan. Maka dari itu tujuan penelitian ini adalah mengetahui standarisasi penerapan metode e-learning pada Universitas Muhammadiyah se-Jawa Tengah. Metode penelitian yang digunakan berupa metode meta-analisis dimana penelitian dilakukan menggunakan hasil dari penelitian sebelumnya untuk menghasilkan kesimpulan dengan analisis deskriptif kualitatif. Adapun hasil dari penelitian ini adalah media penerapan e-learning yang sesuai standarisasi SCORM yaitu Schoology dan portal e-learning. Hal tersebut menandakan Universitas Muhammadiyah se-Jawa Tengah ternyata belum maksimal dalam penerapan standarisasi konsep e-learning.
\end{abstract}

Kata-kata kunci: meta-analisis, e-learning, SCORM.

\begin{abstract}
The quality of education is a measure of the success of an educational institution to be able to survive in changing times. Therefore the need for technology and information is very necessary that must work together in the world of education. The development of education using e-learning is a necessity so that the quality standards of education can be improved. Therefore the purpose of this research is the aim of standardizing the application of e-learning methods at the University of Muhammadiyah in Central Java. The research method used consisted of a meta-analysis method in which the research was conducted using the results of previous studies to produce conclusions with qualitative descriptive analysis. The results of this study are the media for implementing e-learning that is in accordance with SCORM standardization, namely Schoology and e-learning portal. This indicates that the Muhammadiyah University in Central Java was not yet optimal in applying the standardization of e-learning concepts.
\end{abstract}

Keywords: meta-analysis, e-learning, SCORM. 


\section{PENDAHULUAN}

Institusi pendidikan saat ini dituntut untuk selalu memperbaharui sistem yang diterapkan sesuai perkembangan zaman. Termasuk perkembangan dalam dunia teknologi dan infomasi yang sering disebut dengan istilah zaman 4.0. Mutu pendidikan menjadi tolak ukur keberhasilan sebuah instansi pendidikan untuk dapat survive dalam anomali perubahan zaman. Jika menilik lebih jauh bahwa pendidikan adalah aset vital yang keberadaannya harus mendapatkan porsi maksimal dalam segala upaya peningkatan kualitas. Maka dari itu pemanfaatan teknologi dan informasi sangat menjadi kebutuhan yang harus bersinergi dalam dunia pendidikan.

Pengembangan pendidikan menggunakan e-learning merupakan suatu kebutuhan agar standar mutu pendidikan dapat ditingkatkan. E-learning merupakan satu penggunaan teknologi informasi yang menurut Rosenberg \& Jeffrey (2001) dalam penyampaian pembelajaran melalui jangkauan luas yang berlandaskan tiga kriteria yaitu: (1) e-learning merupakan jaringan dengan kemampuan untuk memperbaharui, menyimpan, mendistribusi dan membagi materi ajar atau informasi, (2) pengiriman sampai ke pengguna terakhir melalui komputer dengan menggunakan teknologi internet yang standar, (3) memfokuskan pada pandangan yang paling luas tentang pembelajaran di balik paradigma pembelajaran tradisional. Dengan demikian urgensi teknologi informasi dapat dioptimalkan untuk pendidikan. Universitas Muhammadiyah sebagai instansi pendidikan dibawah naungan Muhammadiyah memiliki peranan sentral dalam menciptakan kualitas mahasiswa unggul dalam dunia pendidikan. Dikalangan akademisi suatu sistem yang terstruktur tentang pendidikan (proses belajar mengajar) menjadi hal yang tidak dapat terpisahkan. Implementasi metode $e$-learning seakan menjadi kebutuhan di zaman 4.0 yang masif akan teknologi informasi. Maka dari itu dilakukan analisa bagaimana penerapan metode e-learning pada Universitas Muhammadiyah se-Jawa Tengah antara lain Universitas Muhammadiyah Purwokerto (UMP), Universitas Muhammadiyah Surakarta (UMS), Universitas Muhammadiyah Purworejo (UMPWR), Universitas Muhammadiyah Magelang (UMMGL) dan Universitas Muhammadiyah Semarang (UNIMUS). Adapun tujuan penelitian ini adalah diperoleh standarisasi kebutuhan konsep e-learning pada kemajemukan setiap Universitas Muhammadiyah seJawa Tengah.

\section{METODE}

Metode penelitian yang digunakan berupa metode meta-analisis dimana penelitian dilakukan menggunakan data sekunder berupa data-data dari hasil penelitian sebelumnya untuk menghasilkan kesimpulan. Meta-analisis merupakan suatu studi observasional retrospektif, dalam artian metode ini dibuat rekapitulasi fakta tanpa melakukan manipulasi eksperimental.

Topik yang dipilih berupa penerapan metode e-learning yang diterapkan disetiap Universitas Muhammadiyah se-Jawa Tengah. Berdasarkan topik yang ada kemudian ditentukan fokus permasalahan yaitu standarisasi metode e-learning. Teknik pengumpulan data berupa dokumen tertulis yang meliputi : buku, artikel prosiding seminar dan artikel jurnal. Analisis data yang digunakan adalah analisis data deskriptif kualitatif dengan merujuk pada data-data hasil kajian naratif terhadap dokumen penelitian yang ditemui. Alur metode penelitian yang digunakan dapat dilihat pada Gambar 1. 


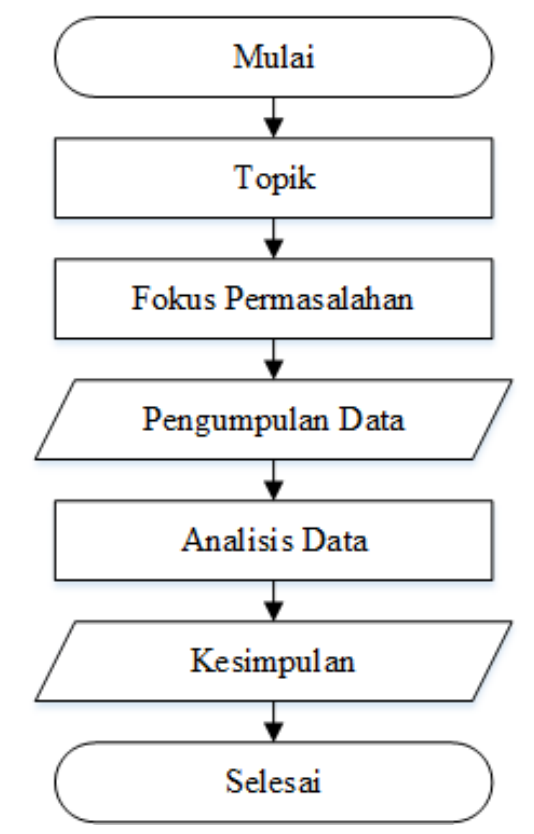

Gambar 1. Flowchart Metode Penelitian

\section{HASIL DAN PEMBAHASAN}

Penelitian ini membahas tentang bagaimana penerapan metode e-learning yang diterapkan di masing-masing universitas dengan berbagai disiplin ilmu. Dari penelitian yang ada didapatkan sebanyak 10 penelitian yang membahas tentang e-learning. Penelitian yang dihimpun diperoleh dari berbagai sumber antara lain artikel jurnal dan artikel prosiding seminar. Penelitian yang ada diperoleh dari media internet dengan memanfaatkan portal $e$-journal masing-masing universitas.

\section{A. Standarisasi penerapan konsep e-learning}

Standarisasi menurut Kamus Besar Bahasa Indonesia (2019) adalah penyesuaian bentuk (ukuran, kualitas dan sebagainya) dengan pedoman (standar) yang ditetapkan. Dengan kata lain standarisasi memiliki peran penting untuk dijadikan pedoman atas sesuatu hal. Tidak terkecuali penerapan konsep e-learning yang ada di Universitas Muhammadiyah se-Jawa Tengah dengan segala kemajemukan yang ada disetiap elemen civitas akademis.

Konsep yang dijadikan dasar untuk standarisasi e-learning yaitu dengan SCORM CAM. Menurut Rice (2006) menjelaskan SCORM (Shareable Content Object Reference Model) adalah standar pendistribusian paket e-learning yang dapat digunakan untuk menampung berbagai spesifikasi dan standar untuk konten e-learning berbasis web dengan mengacu pada interoperability, accesibility, dan reusability. Tujuan SCORM adalah upaya standarisasi e-learning dengan Learning Management Systems (LMS).

Mackenzie (2004) memaparkan bahwa standarisasi diperlukan untuk menjamin akuntabilitas konten pembelajaran yang digunakan pada e-learning. Model pembelajaran e-learning harus memenuhi standarisasi berikut:

1. Accessibility, kemampuan untuk mencari dan mengakses komponen intruksional dari suatu lokasi dan mengirimkannya ke banyak lokasi lain.

2. Adaptability, kemampuan untuk menyesuaikan materi sesuai dengan kebutuhan pribadi dan organisasi.

3. Affordability, kemampuan untuk meningkatkan efisiensi dan produktifitas dengan mengurangi biaya dan waktu yang dibutuhkan dalam pengiriman materi. 
4. Durability, kemampuan bertahan dari perkembangan dan perubahan teknologi tanpa banyak mengeluarkan biaya untuk mendesain, mengkonfigurasi serta penyimpanan ulang.

5. Interoperability, kemampuan untuk mengambil komponen-komponen materi yang dikembangkan di suatu lokasi dengan kelengkapan tool atau platformnya dan menggunakannya di tempat lain dengan tool atau platform yang berbeda.

6. Reusability, kemudahan menggabungkan dan menggunakan kembali komponenkomponen materi dalam aplikasi-aplikasi dan konteks-konteks bertingkat.

\section{B. Content Aggregation Model (CAM)}

Content Aggregation Model dapat digunakan untuk membuat aturan pedagogi untuk desainer materi pembelajaran. Content Aggregation Model memiliki beberapa komponen penting, dintaranya Assets, Shareble Content Object (SCO) dan Content Aggregation. Sebuah materi pembelajaran juga terdiri dari beberapa asset, diantaranya semua media teks, gambar, suara, halaman web, tugas, quiz atau data apapun yang dapat ditampilkan melalui browser. Sebuah asset memiliki keterangan mengenai dirinya sendiri dengan menggunakan Asset Metadata.

1. Asset

Asset adalah blok bangunan yang utama dari sebuah learning resource. Asset merupakan representasi elektronik dari media seperti teks, gambar, suara, objek penelitan atau bagian data lain yang dapat diolah oleh web client dan bisa ditampilkan.

2. Shareable Content Object (SCO)

Sekumpulan dari asset dimana didalamnya terdapat sebuah asset yang dapat dijalankan pertama kali dengan memanfaatkan SCORM Run Time Environment.

3. Content Aggregation

Content Aggregation adalah sebuah peta (struktur materi) yang dapat digunakan untuk menggabungkan berbagai bahan pelajaran SCO menjadi satu modul pembelajaran yang utuh. Content Aggregation juga mendefinisikan struktur materi yang digunakan sebagai mekanisme untuk menentukan urutan sebuah materi pembelajaran yang akan ditampilkan.

\section{Media penerapan e-learning}

Aspek yang akan menjadi pembahasan berupa media penerapan e-learning yang digunakan dengan kesesuaian standarisasi penerapan e-learning. Berikut merupakan hasil penelitian yang ada.

\section{Schoology}

Menurut Aminoto \& Pathoni (2014) menjelaskan bahwa Schoology merupakan salah satu laman web yang berbentuk web sosial. Schoology menawarkan pembelajaran sama seperti di dalam kelas secara percuma dan mudah digunakan seperti Facebook. Tampilan website Schoology dapat dilihat pada Gambar 2. 


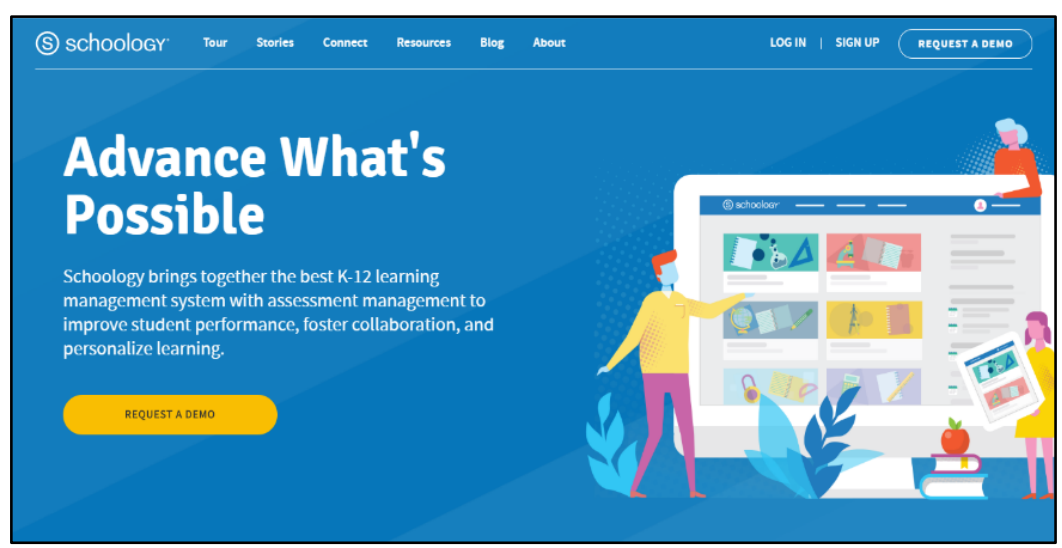

Gambar 2. Website Schoology

Adapun beberapa fitur yang ada di Schoology berupa kursus (course), kelompok (groups), sumber belajar (resources). Pada menu course dapat dibuat soal kuis atau latihan soal-soal berbentuk choice (pilihan ganda), mencocokan atau menjodohkan, benar-salah, isian (singkat), dan lain-lain. Schoology juga menyediakan jenis soal yang mengandung gambar, simbol dan equation. Soal-soal biasanya berbentuk tugas bisa dikerjakan dirumah dan instructor bisa mengakses dari jarak jauh. Fasilitas lain yaitu absensi, analytic, blog, chatting dan pengelolaan nilai (grade) hasil quiz atau aktivitas lain. Dengan kata lain Schoology adalah website penyedia layanan e-learning untuk menunjang pembelajaran pendidikan.

Penelitian yang dilakukan oleh Assidik (2018) memaparkan bahwa perkuliahan MKDU bahasa Indonesia mengalami kendala rendahnya kemampuan mahasiswa dalam membuat karya ilmiah. Maka dari itu penelitian ini memanfaatkan media e-learning Schoology dengan hasil yaitu Schoology dapat memberikan kemudahan, kemanfaatan dan kemenarikan selama pembelajaran MKDU bahasa Indonesia serta dihasilkan 95\% mahasiswa mencapai ketuntasan aspek kognitif untuk aspek afektif dan psikomotor.

\section{Portal E-learning Universitas}

Portal e-learning ini merupakan fasilitas universitas yang digunakan sebagai penunjang kegiatan pembelajaran dengan memanfaatkan media internet/elektronik.

Penelitian yang dilakukan oleh Fathurohman \& Al Hamidy (2010) menjelaskan tentang penerapan pembelajaran e-learning di Fakultas Kedokteran Universitas Muhammadiyah Semarang pada mata kuliah Parasitologi. Penerapan pada penelitian ini menggunakan portal e-learning universitas yang mana ditunjang oleh berbagai referensi berupa e-book, e-journal dan Net-Meeting. Adapun hasil dari penelitian menunjukan bahwa kapasitas internet (bandwidth) relatif masih kecil untuk penerapan e-learning di Fakultas Kedokteran, belum semua dosen memanfaatkan portal ini serta ternyata mahasiwa telah cukup aktif dalam pembelajaran. Tampilan portal e-learning yang digunakan dapat dilihat pada Gambar 3. 


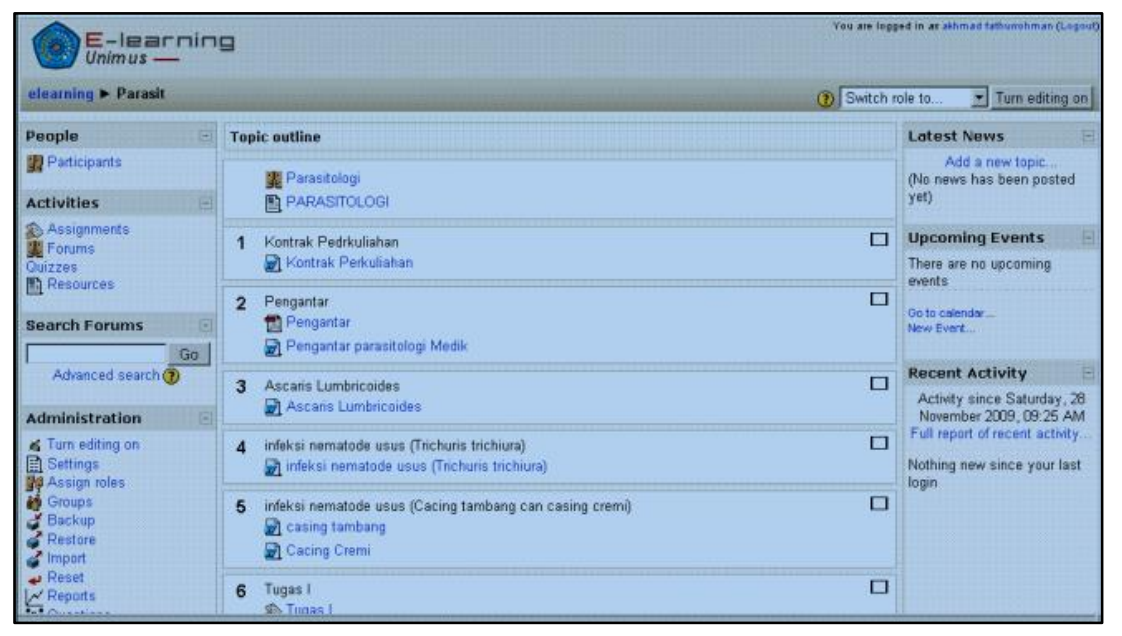

Gambar 3. Tampilan Portal E-Learning UNIMUS

Menurut Fathurohman \& Al Hamidy (2010) menjelaskan bahwa portal e-learning ini disiapkan sebagai acuan dasar pada setiap mata kuliah yang ada. Portal ini menyediakan fasilitas pengelolaan perkuliahan. Dosen dapat mengembangkan materi pembelajaran berbasis web, membuat tugas, kuis, soal ujian dan sebagainya yang dapat dikomunikasikan langsung dengan mahasiswa.

Penelitian lainnya dilakukan oleh Suprayitno \& Rohman (2018) mengemukakan pengantar probabilitas timbul karena pikiran-pikiran manusia yang berhubungan dengan ide, proses dan penalaran. Di dalam penelitian ini digunakan model Realistic Matematics Education (RME) dengan berbantuan e-learning. Hasilnya adalah penerapan model pembelajaran realistic matematics education berbantuan e-learning dapat meningkatkan ketrampilan proses hal ini ditentukan persentase pra siklus 55\% kemudian siklus I 65\% mengalami peningkatan pada siklus II $85 \%$.

\section{Prototype}

Penelitian yang dilakukan oleh Sulistyaningsih, Purnomo, \& Aziz (2019) menjelaskan tentang manipulatif matematika berdasarkan e-learning dan pembentukan karakter dengan mengembangkan learning design (LD). Hasilnya yaitu hasil belajar kelas eksperimen memiliki kemadirian dan tanggung jawab yang lebih tinggi serta mampu menghasilkan banyak manipulatif dan memiiliki kualitas yang lebih baik.

Penelitian selanjutnya dilakukan oleh Budiastuti \& Nugraheni (2015) yang memaparkan pentingnya kebutuhan akan inovasi baru dalam mata kuliah Extensive Reading. Maka dalam hal ini diperlukan sistem e-learning bukan hanya menggunakan video atau powerpoint tertapi menciptakan collaborative learning. Hasil dari penelitian ini adalah pembuatan prototype e-learning berbasis web pada mata kuliah Extensive Reading ternyata dapat meningkatkan hasil belajar sebesar $18,55 \%$. Adapun prototype yang dikembangkan dapat dilihat pada Gambar 4. 


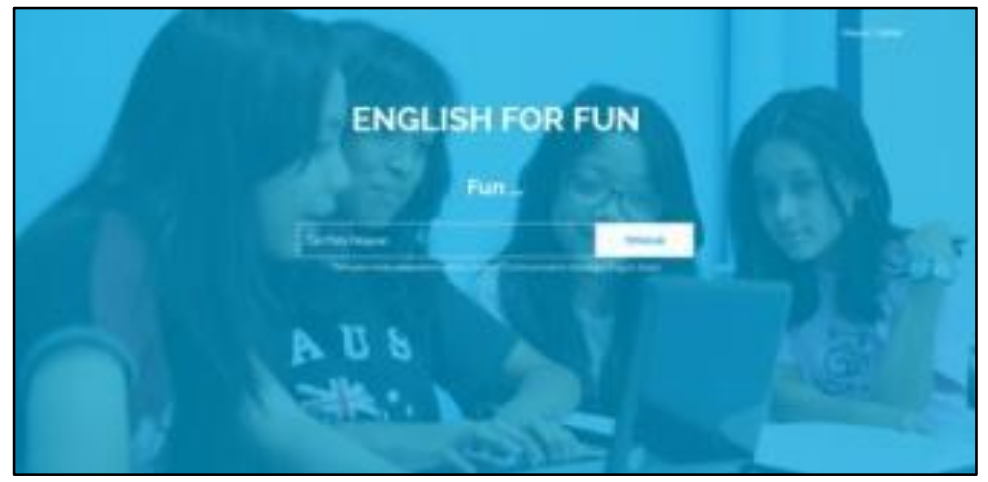

Gambar 4. Prototipe E-Learning Extensive Reading

Prototype yang dikembangkan merupakan hasil inovasi dari pembelajaran konvensional yang diterapkan dalam mata kuliah Extensive Reading. Salah satu fitur yang dapat digunakan adalah penginputan materi oleh dosen dan kemudian mahasiswa terkait dapat berdiskusi atau bertanya pada forum yang disediakan.

Penelitian selanjutnya dilakukan oleh Widyanto (2015) memaparkan pemanfaatan pesan teks berbasis SMS. Test berbasis SMS yang memanfaatkan SMS Gateway merupakan solusi dari permasalahan tersebut. Tujuan dari penelitian ini adalah menyediakan layanan ujian yang praktis dan murah dengan memanfaatkan layanan SMS. Hasil dari penelitian ini adalah bahwa Aplikasi Mobile Test berbasis SMS Gateway ini dapat digunakan sebagai media ujian online alternatif. Tampilan SMS Gateway yang dimaksud dapat dilihat pada Gambar 5.

Aplikasi ujian on line berbasis perangkat mobile dengan memanfaatkan sms untuk registrasi dan mengerjakan soal ujian. Sistem ini dipergunakan admin untuk mengelola user dan user mengelola soal ujian. Pengerjaan soal ujian dilakukan dengan menjawab SMS tersebut, bila semua soal telah selesai dikerjakan maka akan muncul skor nilainya. Bila masih belum lulus, bisa mengulang sebanyak dua kali lagi.

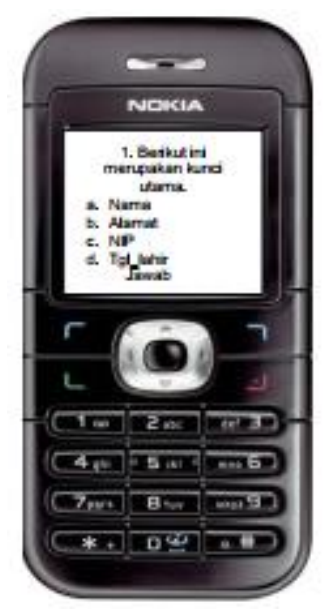

\section{Gambar 5. Tampilan SMS Gateway}

Penelitian lainnya dilakukan oleh Nasrudin \& Kurniawan (2016) menjelaskan pengembangan membuat konten e-learning melalui Microsoft Learning Content Development System (LDCS). Hasil dari penelitian ini yaitu proram LCDS memiliki 
beberapa kekurangan yaitu hanya bisa satu jenis tulisan, tool preview tidak bisa muncul dan perlunya local host untuk publikasi konten LDCS.

\section{Sosial Media}

Penelitian yang dilakukan oleh Faizah, Fakhrudin, \& Bagiya (2018) menjelaskan penerapan media pembelajaran Youtube berbasis pendekatan ilmiah pada pembelajaran Retorika Dakwah Pendidikan di Universitas Muhammadiyah Purworejo. Pendekatan ilmiah yang digunakan meliputi mengamati, menanya, mengeksplorasi, mengasosiasi dan mengomunikasikan. Adapun hasil dari penelitian ini yaitu adanya respon positif terhadap penggunaan media ini yaitu lebih mendalami materi setelah sampai dirumah. Video yang disajikan pada tahap melihat atau mengamati menarik dan sesuai dengan materi dakwah. Hal ini diperkuat dengan komentar mahasiswa yang menyatakan bahwa video yang disajikan telah disertai penjelasan yang jelas.

\section{Mobile}

Pemanfaatan perangkat mobile untuk keperluan dunia pendidikan yang mana dalam hal ini juga diimplementasikan pada e-learning. Penelitian dari Kusuma \& Abida (2019) menjelaskan tentang pemanfaatan mobile learning matematika pada materi SPLDV. Teknologi mobile dapat diakses kapan saja dan dimana saja sehingga fleksibelitasnya sangat tinggi untuk diterapkan dalam pembelajaran. Hasil dari penelitian ini adalah terciptanya keefektifan belajar dan daya kreatif sehingga suasana pembelajaran lebih menarik. Perangkat mobile learning yang digunakan dapat dilihat pada Gambar 6.

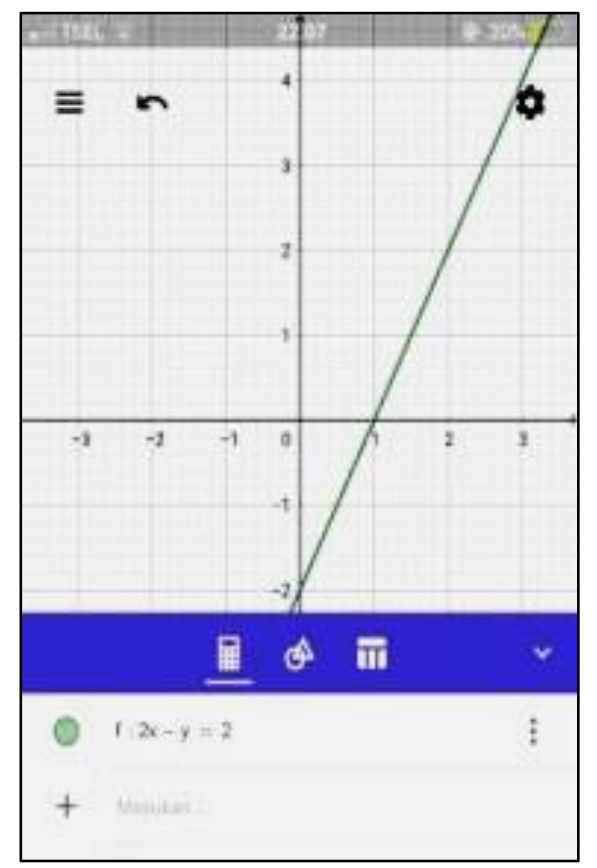

Gambar 6. Mobile Apps untuk pembelajaran

Aplikasi mobile yang digunakan bernama Geogebra dengan tujuan agar proses pembelajaran dalam dengan mudah dilakukan. Geogebra dapat membantu menyelesaikan SPLDV dengan penjelasan yang menarik disertai dengan grafik dan penyelesaian yang akurat. 
Berikut disajikan beberapa portal e-learning pada Universitas Muhammadiyah seJawa Tengah. Portal e-learning yang ditampilkan melalui gambar halaman awal ini merupakan portal $e$-learning yang disediakan oleh pihak universitas terkait. Berbagai data yang dihimpun atau gambar diambil dari website resmi universitas bersangkutan. Universitas Muhammadiyah Purwokerto (2019) memiliki portal e-learning yang cakupannya sudah bisa diakses oleh seluruh mahasiswa yaitu bernama OnClass, dapat dilihat pada Gambar 7.

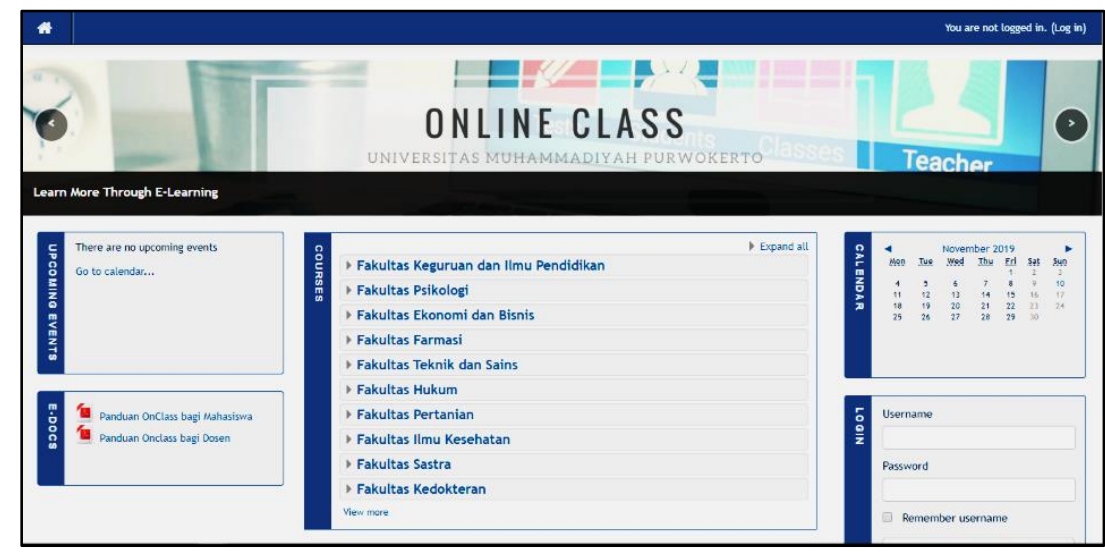

Gambar 7. Portal E-Learning Universitas Muhammadiyah Purwokerto

Portal e-learning ini dikembangkan menggunakan Learning Management System (LMS) Moodle. LMS ini bisa diakses dan digunakan oleh semua fakultas yang ada di Universitas Muhammadiyah Purwokerto. Beberapa fitur yang ada di OnClass ini antara lain pengaturan profile, mengakses sumber ajar (format book, folder, file, page, URL). Dilengkapi juga dengan berbagai aktivitas lainya berupa chatting (mengirim pesan ke sesama user), forum (tempat untuk berdiskusi tentang mata kuliah yang ada), penugasan (digunakan untuk mengirimkan tugas), quiz (latihan untuk menguji pemahaman dari materi ajar). Pada halaman OnClass ini terdapat list fakultas beserta Program Studi yang ada didalamnya, jika dosen pengampu menggunakan portal e-learning ini maka akan muncul mata kuliah yang akan digunakan selama pembelajaran.

Universitas Muhammadiyah Magelang (2019) memiliki portal e-learning yang disajikan dalam Gambar 8.

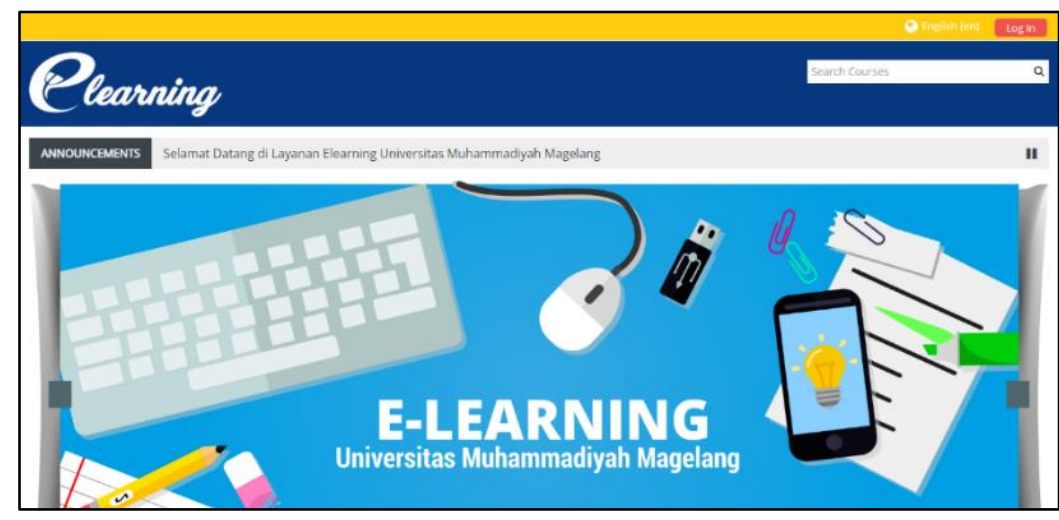

Gambar 8. Portal E-Learning Universitas Muhammadiyah Magelang 
Portal e-learning ini merupakan layanan atau fasilitas untuk mempermudah pembelajaran secara online. Layanan ini digunakan untuk mahasiswa dan dosen. Pada halaman yang tersedia memuat daftar fakultas beserta Program Studi yang ada. Mata kuliah sudah terdaftar secara otomatis pada setiap Program Studi yang tersedia. Aktivitas lain juga adanya forum untuk diskusi yang dapat diakses dengan mengikuti pembelajaran yang ada. Berbagai fitur dapat dilihat dengan login ke dalam sistem tetapi harus memasukan username dan password terlebih dahulu.

Universitas Muhammadiyah Purworejo (2019) memiliki portal e-learning yang disajikan pada Gambar 9.

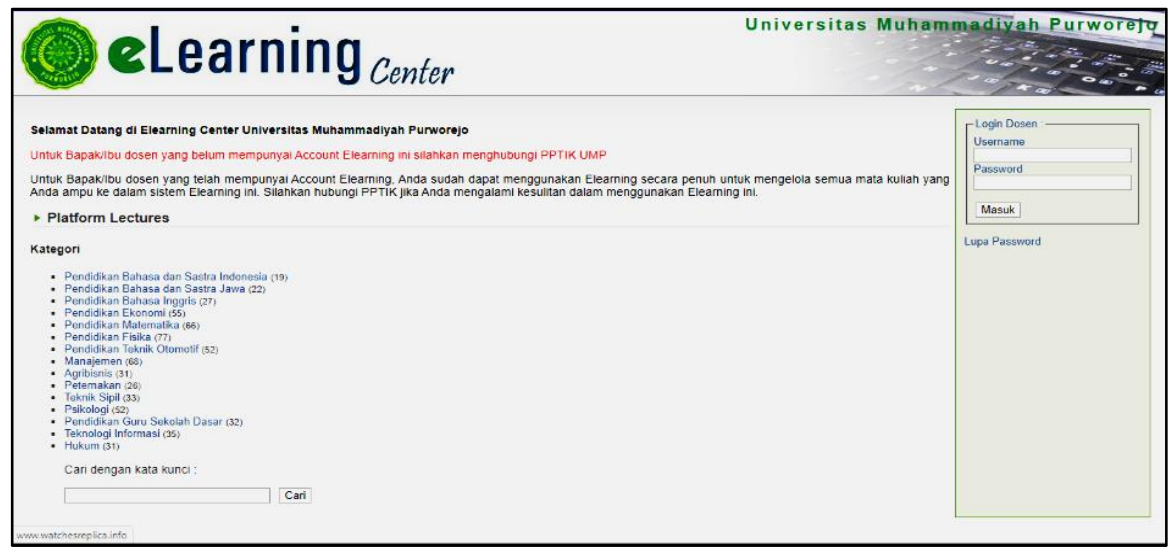

Gambar 9. Portal E-Learning Universitas Muhammadiyah Purworejo

E-Learning center ini memiliki beberapa menu antara lain kategori yang memuat semua fakultas, disetiap fakultas memiliki informasi daftar mata kuliah yang terdaftar pada sistem e-learning ini. Detail setiap mata kuliah memiliki menu yaitu deskripsi mata kuliah, agenda, pengumuman, dokumen, latihan-latihan, alur pembelajaran, assignments, forum-forum, kelompok-kelompok, users, diskusi dan wiki.

Fakultas Kedokteran Gigi UMS (2019) memiliki portal e-learning yang lingkupnya tingkat fakultas, dalam hal ini portal e-learning yang disajikan adalah dari Fakultas Kedokteran Gigi dapat dilihat pada Gambar 10.

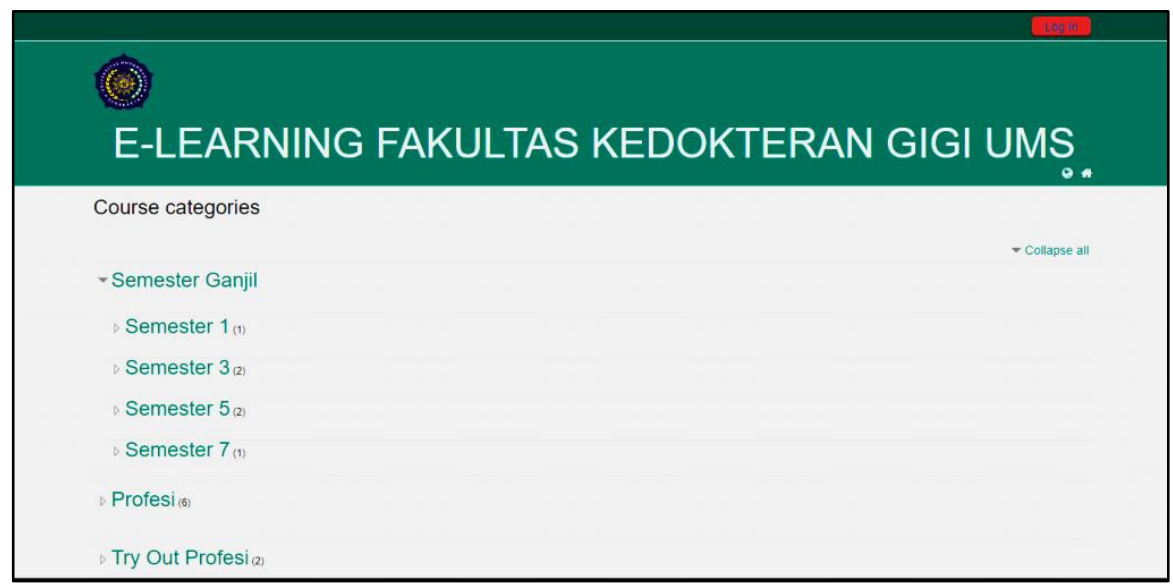

Gambar 10. Portal E-Learning FKG Universitas Muhammadiyah Surakarta 
Dari penelusuran yang dilakukan dijejaring internet, hanya ditemukan portal $e$ learning tingkat fakultas kedokteran gigi. Ada beberapa fitur yang terdapat pada portal ini sebagai berikut daftar semester, profesi serta menu tryout. Semester menampilkan tingkatan semester dan disetiap semester menampilkan mata kuliah yang menggunakan $e$ learning ini. Untuk akses tryout hanya bisa dilakukan setelah login.

Fakultas Matematika dan Ilmu Pengetahuan Alam UNIMUS (2019) memiliki portal e-learning tingkat fakultas yang dapat dilihat pada Gambar 11.

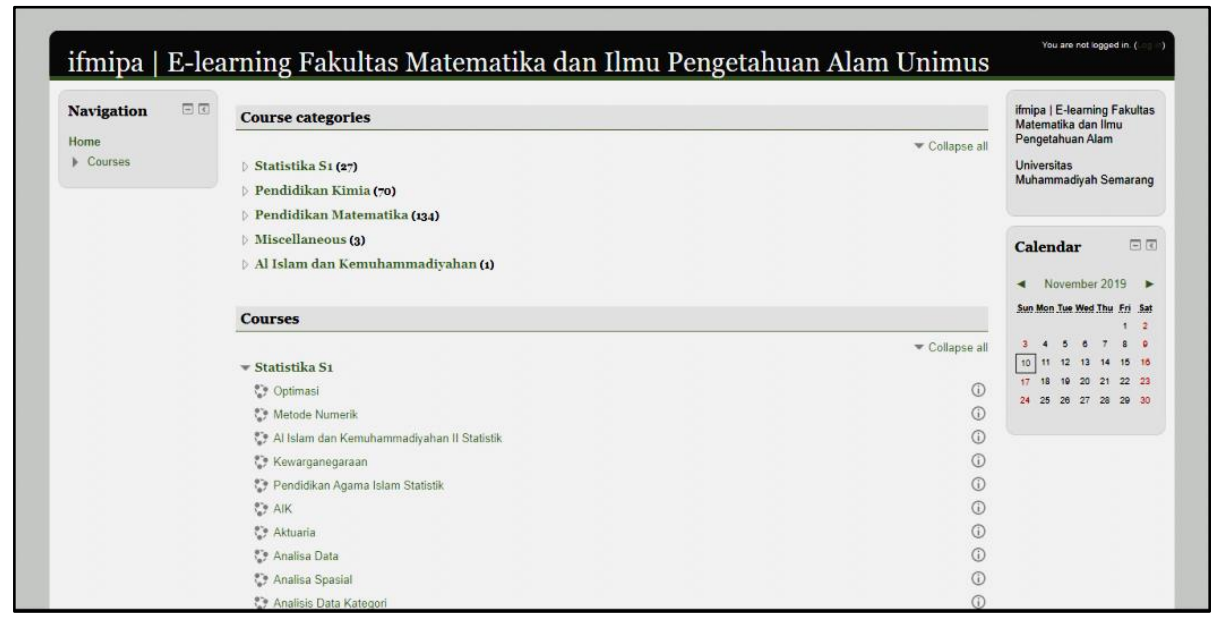

Gambar 11. Portal E-Learning IFMIPA Universitas Muhammadiyah Semarang

Penerapan e-learning pada Universitas Muhammadiyah Semarang terbagi disetiap fakultas. Setiap fakultas memiliki sistem e-learningnya sendiri, disini diambil contoh $e$ learning yang diterapkan pada Fakultas Matematika dan Ilmu Pengetahuan Alam. Dapat portal ini dapat dijabarkan dengan berbagai menu yang tersedia antara lain, course categories (menampilkan daftar program studi), course (menampilkan berbagai mata kuliah berserta dosen yang mengampu pada mata kuliah tersebut).

Sebagai media komparasi disajikan media berbasis portal e-learning yang disediakan universitas untuk dijadikan perbandingan standarisasi yang diterapkan. Berdasarkan standarisasi yang ditetapkan dengan konsep SCORM (Shareable Content Object Reference Model) CAM didapatkan data sebagai berikut:

\section{Standarisasi Media}

Media yang digunakan untuk mencapai standarisasi SCORM (Shareable Content Object Reference Model) CAM yaitu media yang menggunakan website atau berbasis website. Maka didapatkan dari 10 penelitian yang diperoleh hanya didapatkan 2 media layanan e-learning yang memenuhi syarat berbasis website yaitu Schoology, portal $e$ learning universitas, ptototype dan sosial media. Sedangkan penerapan media berupa SMS gateway dan mobile apps tidak memenuhi standarisasi yang ditetapkan karena bukan berbasis website.

\section{E. Aspek Standarisasi}


Aspek yang menjadi standarisasi adalah Accessibility, Adaptability, Affordability, Durability, Interoperability, Reusability. Adapun aspek dalam pemenuhan standarisasi dapat dijabarkan sebagai berikut:

1. Accessibility yaitu dapat diakses secara online dan menyediakan fasilitas pencarian (search engine) dari media yang digunakan yang memenuhi aspek ini adalah Schoology, portal e-learning, prototype dan sosial media. Semua media tersebut memiliki fitur search engine yang digunakan untuk mempermudah mencari komponen instruksional.

2. Adaptability yaitu materi yang dibuat telah disesuaikan dengan kurikulum yang berlaku. Pada aspek ini didapatkan bahwa yang memenuhi aspek ini yaitu Schoology, portal e-learning dan prototype. Media tersebut dapat disesuaikan dengan kurikulum karena pengembangannya seperti Schoology dapat disisipkan konten berbasis SCORM. Kemudian portal e-learning serta prototype merupakan pengembangan media e-learning yang dapat ditinjau secara kebutuhan dalam lingkup tertentu. Dalam penerapan sosial media tidak bisa dijadikan patokan untuk penyesuaian kurikulum karena hanya sebagai media pelengkap untuk e-learning.

3. Affordability yaitu efisiensi dan produktifitas dapat dilihat jika digunakan secara masal. Berdasarkan aspek tersebut didapatkan bahwa yang memenuhi aspek ini yaitu Schoology, portal e-learning. Kedua media tersebut memiliki potensi yang bisa digunakan oleh banyak pengguna sehingga pada penerapannya Schoology dan portal e-learning bisa memenuhi aspek ini. Schoology sebagai layanan penyedia e-learning serta portal e-learning yang dipergunakan untuk civitas Universitas. Penggunaan prototype dan sosial media hanya diperuntukan untuk pembelajaran yang spesifik sehingga tidak bisa digunakan secara masal.

4. Durability yaitu setiap perkembangan dapat diikuti hanya dengan mem-packing ulang sehingga tidak perlu biaya untuk membuat dari awal lagi. Pada aspek ini didapatkan bahwa yang memenuhi aspek yaitu Schoology dan portal e-learning. Sedangkan prototype merupakan rangka awal sehingga belum bisa diajadikan patokan untuk media e-learning secara kompleks. Hal serupa juga sama dengan sosial media yang digunakan sebagai media yang disediakan stakeholder non-education.

5. Interoperability yaitu media untuk menyimpan dan mengambil semua asset yang tersedia dan digunakan kembali pada LMS. Pada aspek ini didapatkan bahwa yang memenuhi aspek yaitu Schoology, portal e-learning dan prototype. Learning Management System (LMS) yang dimaksud adalah media e-learning berbasis website sehingga media tersebut bisa terpenuhi. Adapun asset yang dipergunakan semua media teks, gambar, suara, halaman web, tugas, quiz atau data apapun yang dapat ditampilkan melalui browser.

6. Reusability yaitu konsep hirarki yang telah disusun memberikan kemudahan dalam mengakses bahan pembelajaran dan memudahkan saat menambah materi tanpa merubah konteks yang ada. Pada aspek ini didapatkan bahwa yang memenuhi aspek yaitu Schoology, portal e-learning dan prototype. Penerapan sosial media hanya sebatas penyedia untuk menampilkan konten video sebagai penunjang pembelajaran. Sedangkan Schoology, portal e-learning dan prototype. 


\section{KESIMPULAN}

Berdasarkan penelitian yang telah dilakukan dengan sumber data atau literatur yang ada dapat disimpulkan bahwa:

1. Penerapan konsep e-learning pada Universitas Muhammadiyah se-Jawa Tengah menggunakan berbagai media berbeda yaitu Schoology, portal e-learning universitas, prototype, sosial media dan mobile. Dari media yang digunakan dapat disimpulkan bahwa belum adanya standarisasi khusus untuk penggunaan media e-learning.

2. Didasarkan pada standarisasi SCORM (Shareable Content Object Reference Model) CAM dapat disimpulkan terdapat dua media yang masuk kualifikasi (standar). Media yang memenuhi standarisasi sesuai aspek yang berupa Accessibility, Adaptability, Affordability, Durability, Interoperability, Reusability pada 1 yaitu Schoology dan portal e-learning.

\section{DAFTAR PUSTAKA}

Aminoto, T., \& Pathoni, H. (2014). Penerapan Media E-Learning Berbasis Schoology Untuk Meningkatkan Aktivitas dan Hasil Belajar Materi Usaha dan Energi Di Kelas XI SMA N 10 Kota Jambi. Jurnal Sainmatika, 8(1), 13-29.

Assidik, G. K. (2018). INTEGRASI SISTEM KELAS MAYA PADA PEMBELAJARAN MKDU BAHASA INDONESIA DI UNIVERSITAS MUHAMMADIYAH SURAKARTA. Prosiding Semnas KBSP V, 422-426.

Budiastuti, R. E., \& Nugraheni, Y. (2015). COLLABORATIVE E-LEARNING BERBASIS WEB PADA MATA KULIAH EXTENSIVE READING. The 2nd University Research Coloquium, 1-5.

Faizah, U., Fakhrudin, M., \& Bagiya. (2018). IMPLEMENTASI MEDIA PEMBELAJARAN YOUTUBE RETORIKA DAKWAH PENDIDIKAN BERBASIS PENDEKATAN ILMIAH DI UNIVERSITAS MUHAMMADIYAH PURWOREJO. Jurnal Bahtera, 10, 424-433.

Fakultas Kedokteran Gigi UMS. (2019). E-Learning. http://elearning.fkg.ums.ac.id/. http://elearning.fkg.ums.ac.id/

Fakultas Matematika dan Ilmu Pengetahuan Alam UNIMUS. (2019). E-Learning IFMIPA UNIMUS. http://ifmipa.unimus.ac.id/. http://ifmipa.unimus.ac.id/

Fathurohman, A., \& Al Hamidy, F. (2010). PENGEMBANGAN MODEL PEMBELAJARAN E-LEARNING DAN PENGARUHNYA TERHADAP HASIL BELAJAR MAHASISWA FAKULTAS KEDOKTERAN UNIVERSITAS MUHAMMADIYAH SEMARANG. Prosiding Seminar Nasional Unimus, 319333.

Kamus Besar Bahasa Indonesia (KBBI). (2019). Standarisasi. Kbbi.Web.Id. https://kbbi.web.id/standardisasi

Kusuma, A. B., \& Abida, R. (2019). PEMANFAATAN MOBILE LEARNING PADA PEMBELAJARAN MATEMATIKA DI ERA REVOLUSI INDUSTRI 4.0. Prosiding Sendika, 5, 229-235.

Mackenzie, G. (2004). SCORM 2004 Primer A (Mostly) Painless Introduction to SCORM Version 1.0.

Nasrudin, \& Kurniawan, H. (2016). PENGEMBANGAN KONTEN E-LEARNING MELALUI LEARNING CONTENT DEVELOPMENT SYSTEM SEBAGAI INOVASI PEMBELAJARAN. Ekuivalen, 24(2), 28-30.

$\overline{\text { (Meta-Analisis Konsep Penerapan ........... Denis Pratama Alwan Azzami, Hindayati Mustafidah) }}$ 
Rice, W. (2006). Moodle-Learning Course Development, Complete Guide To Successful Learn Using Moodle. Packt Publishing.

Rosenberg, R., \& Jeffrey, M. (2001). E-learning : Strategies for Delivering Knowledge in the Digital Age. McGraw-Hill Professional.

Sulistyaningsih, D., Purnomo, \& Aziz, A. (2019). Development of Learning Design for Mathematics Manipulatives Learning based on E-learning and Character Building. International Electronic Journal of Mathematics Education, 14(1), 197-205.

Suprayitno, I. J., \& Rohman, A. (2018). PENERAPAN MODEL RME BERBANTUAN E-LEARNING UNTUK MENINGKATKAN KETRAMPILAN PROSES MAHASISWA. Seminar Nasional Edusainstek FMIPA UNIMUS, 9-15.

Universitas Muhammadiyah Magelang. (2019). Elearning System. https://elearning.ummgl.ac.id/. https://elearning.ummgl.ac.id/

Universitas Muhammadiyah Purwokerto. (2019). Online Learning Class. onclass.ump.ac.id. https://onclass.ump.ac.id/

Universitas Muhammadiyah Purworejo. (2019). E-Learning Center. http://elearning.umpwr.ac.id/. http://elearning.umpwr.ac.id/

Widyanto, R. A. (2015). MOBILE TEST BERBASIS SMS GATE WAY SEBAGAI PELENGKAP E-LEARNING. Prosiding Seminar Nasional Seri Ke-5, 488-493. 